\title{
GENESiS: creating a composite index of the vulnerability to anxiety and depression in a community-based sample of siblings
} \author{
T Eley ${ }^{1}$, D Goldberg' ${ }^{1}, \mathrm{JGray}^{3}, \mathrm{~A} \mathrm{Mann}^{3}, \mathrm{M} \mathrm{Owen}{ }^{4}$ and R Plomin ${ }^{1}$ \\ ${ }^{1}$ Social, Genetic \& Developmental Psychiatry Research Centre, London, UK \\ ${ }^{2}$ Institute for Behavioral Genetics, University of Colorado, Boulder, CO, USA \\ ${ }^{3}$ Institute of Psychiatry, de Crespigny Park, Denmark Hill, London \\ ${ }^{4}$ University of Wales College of Medicine, Heath Park, Cardiff, UK
}

PC Sham ${ }^{1}$, A Sterne ${ }^{1}$, S PurcelI ${ }^{1}$, S Cherny $^{1,2}$, M Webster $^{1}$, F Rijsdijk $^{1}$, P Asherson ${ }^{1}$, D Ball ${ }^{1}$, I Craig $^{1}$,

\begin{abstract}
There is considerable evidence for a unitary and dimensional view of the genetic vulnerability to symptoms of anxiety and depression. The GENESiS (Genetic Environmental-Nature of Emotional States in Siblings) Study aims to use a multivariate approach to detect genetic loci that contribute to individual differences in this vulnerability dimension. The study used the UK General Practice Research Framework to generate a community-based sample of siblings. Questionnaire measures of anxiety/depression included the short form of the neuroticism scale from the revised Eysenck Personality Questionnaire (EPQ-N), the General Heal th Questionnaire (GHQ-12), and the anxious arousal and high positive affect subscales from the Mood and Anxiety Symptoms Questionnaire (MASQ-AA and MASQ-HPA). Genetic model-fitting of 2658 unselected sibships provided evidence for a single common genetic (familial) factor that accounted for a substantial proportion of the genetic variances and covariances of these four measures. Using the parameter estimates of this model, we constructed a composite index of this common genetic factor. This index, which has a sib correlation of 0.22 , will be used as a quantitative phenotype in the molecular genetic phase of GENESiS. Twin Research (2000) 3, 316-322.
\end{abstract}

Keywords: depression, anxiety, neuroticism, sibships, genetics, vulnerability

\section{Introduction}

There is substantial evidence from epidemiological and genetic studies for a single dimension of genetic vulnerability to anxiety and depression. ${ }^{1-3}$ Numerous studies have documented a substantially greater degree of co-morbidity than expected by chance between the two disorders. ${ }^{4-9}$ For example, in the Zurich study conducted by Angst and DoblerMikola $a^{4}$ the 1-year prevalence rate of major depression co-occurring with anxiety was $36 \%$, while for the population sample as a whole, the prevalence rate for major depression was only $7.0 \%$. The two disorders also have a similar profile of epidemiological risk factors; Eaton and Ritter ${ }^{5}$ used a psychiatric diagnostic interview to devise an index for anxiety and an index for depression, and found these two indices to have very similar 'sociodemographic fingerprints'.

Correspondence: Dr PC Sham, SGDP Research Centre, Institute of Psychiatry, London, SE5 8AF UK. Tel: 0207848 0892; Fax: 020 7848 0866; E-mail: P.Sham@op.kcl.ac.uk

Received 7 September 2000; revised 29 September 2000; accepted 3 October 2000
Goldberg et al ${ }^{6}$ examined the symptoms shared by common psychiatric disorders in a primary care setting. One of their core assumptions was that common psychiatric disorders would fit a dimensional rather than a categorical diagnostic model..$^{10,11}$ They factor-analysed the 28-item General Health Questionnaire and interview items from the Psychiatric Assessment Schedule, and found two highly correlated $(r=0.7)$ factors that represented anxiety and depression dimensions. This suggested a single major dimension of symptoms that accounted for $70 \%$ of the variance of both anxiety and depression, and a second dimension that explained the remaining $30 \%$ of the variance of symptoms that are more specific to anxiety or depression. They speculated that the major dimension reflected a biological vulnerability to psychiatric disorder, while the secondary dimension was indicative of environmental influences.

The hypothesis that there is a shared genetic vulnerability to anxiety and depression has been supported by extensive quantitative genetic research. ${ }^{1,2,12-15}$ For example, in a study of nearly 4000 twin pairs, Kendler et $\mathrm{al}^{13}$ showed that genes acted in a non-specific fashion to influence the general level of symptoms of anxiety and depression. 
Similarly, in another study of 1030 female twin pairs, Kendler et al $^{15}$ showed that genetic influences on phobias, panic disorder, bulimia nervosa, generalised anxiety disorders, major depression, and alcoholism fell into two factors. The first loaded heavily on phobia, panic disorder, and bulimia nervosa; the second loaded on to major depression and general ised anxiety disorder; the genetic vulnerability to alcoholism was largely independent of both factors. These results offer strong support for a single genetic dimension in the vulnerability to anxiety and depression.

There is evidence to suggest that the general vulnerability to anxiety and depression may be indexed by the personality scale of neuroticism. ${ }^{16}$ Jardine et al ${ }^{17}$ showed in a study of 3810 Australian twin pairs that variations in symptoms of anxiety and depression were largely dependent on the same factors as those that determined neuroticism. Similarly, in the Virginia twin sample, neuroticism was found to be strongly predictive of an onset of major depression in a one-year period. ${ }^{18}$ Furthermore, genetic factors accounted for approximately $70 \%$ of the correlation between neuroticism and major depression.

The evidence reviewed above supports a dimensional and unitary view of the vulnerability to anxiety and depression. The goal of the GENESiS (Genetic Environmental-Nature of Emotional States in Siblings) Study is to apply quantitative genetic methodology to a large community-based sample of sibling pairs in order to identify quantitative trait Ioci (QTL) for a general dimension of vulnerability to anxiety and depression. Although there is evidence that neuroticism is an index of this vulnerability, no study has addressed this issue using siblings. Therefore, GENESiS adopts an empirical, multivariate approach for the measurement of this Iatent variable. In addition to neuroticism, we also include three other scales that measure general mental health, autonomic anxiety and mood. Our hypothesis is that quantitative genetic modelling of these four measures will confirm a single underlying genetic (familial) vulnerability. This would allow the construction of a single composite index of the genetic vulnerability to anxiety and depression that would be optimal for future molecular genetic studies.

\section{Methods}

\section{Subjects}

The GENESiS study is based in the United Kingdom. Subjects were recruited through the Medical Research Council's General Practice Research Framew ork (GPRF). The GPRF was set up more than 20 years ago to enable high quality data to be collected on large-scale community samples. The GPRF now comprise more than 1000 large practices distributed throughout the United Kingdom.

The participating GPs identified the names and addresses of all patients on their registers aged between 20 and 55 years, excluding those with severe learning disabilities or psychotic illness. We also suggested that those patients who were particularly vulnerable (eg with terminal illnesses) be excluded, although this was left to the GP's discretion. An initial notification letter was sent to the subjects to inform them that their GP practice was involved in a new study about depression and anxiety, and that they would be sent a questionnaire (see Eaker et al ${ }^{19}$ or Etter et $\mathrm{al}^{20}$ for more information on the benefits of notification letters in mailing surveys). The subjects were able to opt-out of the study by calling a freephone number or contacting the GP. In the second mailing, a questionnaire (called the index sibling questionnaire) was sent together with an introduction letter from the GP. Four weeks after the questionnaire was mailed, a general reminder letter was sent to all subjects. Finally, a further questionnaire was sent to the non-responders four weeks after the general reminder letter. From the returned index sibling questionnaires we generated a mailing list for non-index siblings. A questionnaire was mailed to non-index siblings approximately one month after the study received the original index sibling questionnaire. A second questionnaire was mailed to the non-responders among the non-index siblings 8 weeks after the first mailing.

In this report, we present an analysis of data collected up to March 1999. By this date, $10 \mathrm{GP}$ practices across England had participated in the study. The GPs reflect the full range of rural and urban practices in the UK. The participating GP practices generated a list of 51806 people. In total, the GPs requested that 421 people be taken out of the mailing list, representing $0.008 \%$ of the overall total . A further 1799 questionnaires were returned due to incorrect addresses (3.5\% of the total). This left a maximum of 49586 index subjects who were actually contacted.

\section{Measures}

The questionnaires to both index subjects and nonindex siblings included several well-validated and standardised instruments for the measurement of anxiety/depression related traits, other personality traits, and psycho-social adversity. The General Heal th Questionnaire (12-item version; GHQ12) was used as a test of general mental health symptoms. ${ }^{21}$ The short form of the neuroticism scale from the revised Eysenck Personality Questionnaire (EPQ-N) 
was used as a measure of trait anxiety. ${ }^{22}$ Short forms of two subscales were used from the Mood and Anxiety Symptoms Questionnai re ${ }^{23}$ to measure level of anxious arousal (MASQ-AA) as well as high positive effect (MASQ-HPA). Other measures such as life events and social problems were also included for future analyses of interactions with anxiety and depression.

\section{Statistical analyses}

Structural equation models were fitted to the sibship data on the four measures: GHQ12, EPQ-N, MASQ$A A$ and $M A S Q-H P A$. When used on twin data under the equal environment assumption, structural equation models are able to partition phenotypic variance into components due to genes, environmental factors shared by siblings, and environmental factors unique to the individual. The current study, which employs a sibship design for the purpose of subsequent linkage and association analysis, cannot discriminate between genetic and shared environmental influences. Nevertheless, there is a substantial literature of studies on adult twins that supports the importance of genetic influences and the lack of important shared environmental influences. $^{14,24}$ We have therefore omitted shared environmental influences from our models. We emphasise that, because of this necessary omission, the 'genetic' effects estimated from our analyses are really familial effects that may contain environmental influences shared by siblings.

Estimates of within-sib/cross-traits correlations were obtained from the entire sample of subjects who returned questionnaires, including those without siblings. Estimates of between-sibs/same-trait correlations, and between-sibs/cross-traits correlations were obtained by doubly entering all possible sibling pairs in sibships of size 2 and 3 . Structural equation models were fitted by maximising the loglikelihood function of the raw sibship data on the four standardised (mean 0, variance 1) measures, pre-adjusted for age and sex, using the $\mathrm{Mx}$ software. $^{25}$ After fitting a saturated model where all means, variances and covariances were free parameters, we proceeded to fit a model with a Cholesky decomposition of the additive genetic effects, and a Cholesky decomposition of non-shared environmental effects. Three further restricted models were examined. The first restricted model replaced the Cholesky genetic factors by a single common genetic factor and four specific genetic factors. We call this the common genetic factor model (see Figure 1). The second replaced the Cholesky environmental factors with a single common environmental factor and four specific environmental factors. We call this the common environmental factor model. The final restricted model was obtained by replacing both Cholesky genetic and environmental factors by common and specific genetic and environmental factors. This is the standard common factor, independent pathways model. ${ }^{26}$

\section{Results}

Response rates and sociodemographic characteristics

The total number of fully completed returned questionnaires for index siblings is 22087 (response rate $45 \%$ ). We also asked people who did not want to take part in the study to return the forms and to complete four demographic measures that included: current employment, level of education, ethnicity, and type of living accommodation. There were 4196 uncompleted returned forms, representing $8.5 \%$ of the overall population who were contacted.

Of the returned index sibling questionnaires, name and contact information was provided for 11656 non-index siblings. By March 1999, 3682 nonindex siblings had returned questionnaires. Table 1 shows the total number of families and sibling pairs in the GENESiS study. Families with more than two siblings generate larger numbers of possible sibling pairs. Thus a family with three siblings generates 3 sibling pairs, whilst a 4-sib family generates 6 sibling pairs. This meant that 2658 families generated a total number of 3944 sib pairs.

The sociodemographic characteristics of the sample are shown in Table2. There is a fairly uniform age distribution and a slight predominance of femal es (58\%). The sample is $98 \%$ Caucasian, which is advantageous for a genetic study to map QTLs. There is a good spread of socio-economic status in the sample.

\section{Summary statistics}

The means of the four measures shown in Table 3 indicate a generally higher level of anxiety and depression in females than in males, which is consistent with the higher preval ence of depression

\begin{tabular}{lcc} 
Table 1 & Distribution of sibship size in the GENESiS study \\
\hline Sibship & Number of & $\begin{array}{l}\text { Number of } \\
\text { individuals }\end{array}$ \\
size & sibships & 4314 \\
\hline 2 & 2157 & 1251 \\
3 & 417 & 304 \\
4 & 76 & 40 \\
5 & 8 & 5909 \\
\hline
\end{tabular}


Table 2 Socio-demographic characteristics of GENESiS sample: whole sample, $n=17,301$ including singleton families; Sibships, $\mathrm{n}=3109$ (ie excluding singl eton families)

\begin{tabular}{|c|c|c|c|c|c|}
\hline $\begin{array}{l}\text { Socio-demographic } \\
\text { characteristics }\end{array}$ & $\begin{array}{l}\text { Whole } \\
\text { sample, \% }\end{array}$ & $\begin{array}{l}\text { Sibships } \\
\%\end{array}$ & & $\begin{array}{l}\text { Whole } \\
\text { sample, \% }\end{array}$ & $\begin{array}{l}\text { Sibships } \\
\%\end{array}$ \\
\hline Age & & & Employment & & \\
\hline $20-29$ years old & 16 & 12 & Manager & 15 & 16 \\
\hline $30-39$ years old & 29 & 31 & Professional & 17 & 23 \\
\hline $40-49$ years old & 31 & 35 & Associate professional/technical & 7 & 6 \\
\hline \multirow[t]{2}{*}{$50+$ years old } & 24 & 22 & Clerical/secretarial & 13 & 13 \\
\hline & & & Craft/manual & 8 & 5 \\
\hline Gender & & & Service & 7 & 5 \\
\hline \multirow[t]{2}{*}{$\%$ male } & 42 & 36 & Sal es & 6 & 5 \\
\hline & & & Plant/machine operative & 2 & 2 \\
\hline Ethnicity & & & Looking after home & 12 & 10 \\
\hline \multirow[t]{2}{*}{$\%$ white } & 98 & 99 & Unemployed & 3 & 2 \\
\hline & & & FT student & 2 & 2 \\
\hline Accommodation & & & Self-employed & 6 & 7 \\
\hline Own home & 76 & 82 & Never-worked & 0.3 & 0.1 \\
\hline Rent & 10 & 8 & Other & 2 & 4 \\
\hline LHA/council & 5 & 4 & & & \\
\hline Living with parents & 8 & 5 & Highest educational level & & \\
\hline \multirow[t]{2}{*}{ Other } & 1 & 1 & No qualifications & 16 & 10 \\
\hline & & & CSE & 9 & 8 \\
\hline Religion & & & O-level/GCSE & 31 & 30 \\
\hline \multirow[t]{5}{*}{$\%$ not religious } & 75 & 81 & A/AS/S level & 14 & 15 \\
\hline & & & HNC & 5 & 4 \\
\hline & & & HND & 4 & 4 \\
\hline & & & Degree & 16 & 22 \\
\hline & & & Postgraduate & 5 & 7 \\
\hline
\end{tabular}

Table 3 Summary statistics of anxiety/depression measures; means and standard deviations (italics)

\begin{tabular}{|c|c|c|c|c|c|c|c|c|}
\hline \multirow[b]{2}{*}{ Age band } & \multicolumn{2}{|c|}{ GHQ-12 } & \multicolumn{2}{|c|}{ EPQ-N } & \multicolumn{2}{|c|}{ HPA } & \multicolumn{2}{|c|}{ AA } \\
\hline & Male & Female & Male & Female & Male & Female & Male & Female \\
\hline $20 \mathrm{~s}$ & $\begin{array}{r}11.34 \\
5.60\end{array}$ & $\begin{array}{r}12.94 \\
5.77\end{array}$ & $\begin{array}{l}5.08 \\
3.32\end{array}$ & $\begin{array}{l}6.55 \\
3.11\end{array}$ & $\begin{array}{r}30.01 \\
8.28\end{array}$ & $\begin{array}{r}27.70 \\
8.52\end{array}$ & $\begin{array}{r}14.95 \\
5.63\end{array}$ & $\begin{array}{r}15.05 \\
5.61\end{array}$ \\
\hline $30 \mathrm{~s}$ & $\begin{array}{r}11.63 \\
5.58\end{array}$ & $\begin{array}{r}12.71 \\
5.76\end{array}$ & $\begin{array}{l}4.50 \\
3.40\end{array}$ & $\begin{array}{l}6.00 \\
3.19\end{array}$ & $\begin{array}{r}29.13 \\
7.97\end{array}$ & $\begin{array}{r}27.29 \\
8.30\end{array}$ & $\begin{array}{r}13.57 \\
5.04\end{array}$ & $\begin{array}{r}13.83 \\
5.02\end{array}$ \\
\hline $40 \mathrm{~s}$ & $\begin{array}{r}11.57 \\
5.38\end{array}$ & $\begin{array}{r}12.61 \\
5.76\end{array}$ & $\begin{array}{l}4.26 \\
3.29\end{array}$ & $\begin{array}{l}5.65 \\
3.33\end{array}$ & $\begin{array}{r}28.69 \\
7.96\end{array}$ & $\begin{array}{r}27.12 \\
8.27\end{array}$ & $\begin{array}{r}13.17 \\
4.82\end{array}$ & $\begin{array}{r}14.00 \\
5.31\end{array}$ \\
\hline $50 s$ & $\begin{array}{r}11.44 \\
5.49\end{array}$ & $\begin{array}{r}12.22 \\
5.60\end{array}$ & $\begin{array}{l}3.98 \\
3.36\end{array}$ & $\begin{array}{l}5.26 \\
3.30\end{array}$ & $\begin{array}{r}28.57 \\
8.15\end{array}$ & $\begin{array}{r}27.59 \\
8.18\end{array}$ & $\begin{array}{r}12.87 \\
4.59\end{array}$ & $\begin{array}{r}14.06 \\
4.87\end{array}$ \\
\hline
\end{tabular}

GHQ-12: General Health Questionnaire, 12-item version; EPQ-N: Eysenck Personality Questionnaire, Neuroticism; HPA: MASQ High Positive Affect (depression, reverse scoring); AA: MASQ Anxious Arousal.

in women reported in previous epidemiological surveys. ${ }^{27}$ There also appears to be a consistent decline of neuroticism with increasing age in both males and females.

The correlations between the four measures, both within individuals and between siblings, are shown in Table 4. The four measures are inter-rel ated within individuals, as indicated by the high within-sib/ cross-traits 'phenotypic' correlations. They are heritable to varying degrees, as indicated by the modest between-sibs/same-trait correlations. They also appear to share a common genetic basis, as indicated by between-sibs/cross-traits correlations that are almost as large as the between-sibs/same-trait correlations.

\section{Model-fitting}

The results of model-fitting, as shown in Table5, favour a model with a common familial factor that loads substantially on all four measures, explaining $23 \%, 18 \%, 15 \%$ and $20 \%$ of the variance of EPQ-N, GHQ-12 MASQ-AA and MASQ-HPA, respectively (Common F, Cholesky E in Table 5). Measure-specific genetic components accounted for a further $14 \%$, $2 \%, 5 \%, 11 \%$ of the variance of these four measures, 
Table 4 Correlation matrices for the four main anxiety/depression measures

\begin{tabular}{|c|c|c|c|c|}
\hline & $\mathrm{N}$ & $\mathrm{GHQ}$ & HPA & $\mathrm{AA}$ \\
\hline \multicolumn{5}{|c|}{$\begin{array}{l}\text { (a) Phenotypic correlations }(n=17031 \text {, } \\
\text { including singl eton families) }\end{array}$} \\
\hline $\mathrm{N}$ & 1.00 & & & \\
\hline GHQ & 0.5491 & 1.00 & & \\
\hline HPA & -0.4617 & -0.5518 & 1.00 & \\
\hline AA & 0.3952 & 0.4267 & -0.3827 & 1.00 \\
\hline \multicolumn{5}{|c|}{$\begin{array}{l}\text { (b) Cross-sibling correlations }(n=3109) \text {, } \\
\text { same-trait (bold) and cross-trait }\end{array}$} \\
\hline $\mathrm{N}$ & 0.1682 & 0.0877 & -0.0962 & 0.0654 \\
\hline $\mathrm{GHQ}$ & 0.1056 & 0.0936 & -0.0884 & 0.0506 \\
\hline HPA & -0.0760 & -0.0683 & 0.1862 & -0.0955 \\
\hline AA & 0.0783 & 0.0843 & -0.1589 & 0.1363 \\
\hline
\end{tabular}

Note: asymmetry due to single-entry for cross-sibling correlations.

Table 5 Fit indices from fitting multivariate genetic models to depression/anxiety variables

\begin{tabular}{llllll}
\hline Model & $-2 \mathrm{lnL}$ & $\mathrm{df}$ & $\Delta-2 \mathrm{InL}$ & \multicolumn{1}{l}{$\Delta$ df $\mathrm{P}$} \\
\hline Saturated model & 58985.024 & 22482 & 0 & 0 & - \\
Cholesky F, Cholesky E & 59209.194 & 22688 & 244.170 & 206 & 0.183 \\
Common F, Cholesky E & 59210.336 & 22690 & 225.312 & 208 & 0.195 \\
Cholesky F, Common E & 59280.406 & 22690 & 295.382 & 208 & 0.0001 \\
Common F, Common E & 59340.175 & 22692 & 355.151 & 210 & 0.0000
\end{tabular}

F: Familial (genetic \& environmental); E: non-shared environment.

leading to heritability estimates of $37 \%, 20 \%, 20 \%$, $31 \%$, respectively. The path diagram of this model is shown in Figure 1.

\section{Creation of composite index}

Using the estimated path coefficients from the common genetic factor to the four measures in the best model, and the estimated correlation matrix of the four measures, we used the method of Thomson $^{28}$ to compute factor scores of the common genetic factor. Let $x$ be a column vector of the observed values of the 4 standardised measures in an individual, then the factor score y of the individual is given by the expected value of the general factor conditional on $\mathrm{x}$, which under the assumption of multivariate normality is given by:

$$
\mathrm{y}=\lambda \Sigma^{-1} \mathrm{x}
$$

where $\lambda$ is a column vector of the estimated path coefficients (which represent the correlations between the common genetic factor and the four measures), $\Sigma$ is the correlation matrix of the four measures. From the estimated values of $\lambda$ and $\Sigma$, the regression coefficients of the four measures EPQ-N, GHQ-12, MASQ-HPA and MASQ-AA, given by the elements in $\lambda \Sigma^{-1}$, are $0.259,0.103,-0.204$ and 0.163 , respectively. The factor score y calculated using these regression coefficients, will be used as a composite index of the underlying common genetic factor in further analyses of this sample. The uni- variate frequency distribution is shown in Figure2; the sibling correlation of this complete index was 0.22 .

We also constructed four other composite indices using the same method, each leaving out one of the four measures. These incomplete indices serve to provide a 'surrogate' for the complete index when one of the four measures is actually missing. The correlations between the complete index and the four incomplete indices are high (see Table6).

\section{Discussion}

We studied the familial architecture of four measures of anxiety and depression in a community sample of sibships, in preparation for future molecular genetic analyses to identify quantitative trait Ioci. The heritability estimate of $37 \%$ for EPQ-N is comparable to those obtained from other family and adoption studies. For example, in the largest family study of personality, correlations for first-degree relatives for personality including neuroticism are about 0.15 , suggesting an upper-limit heritability estimate of

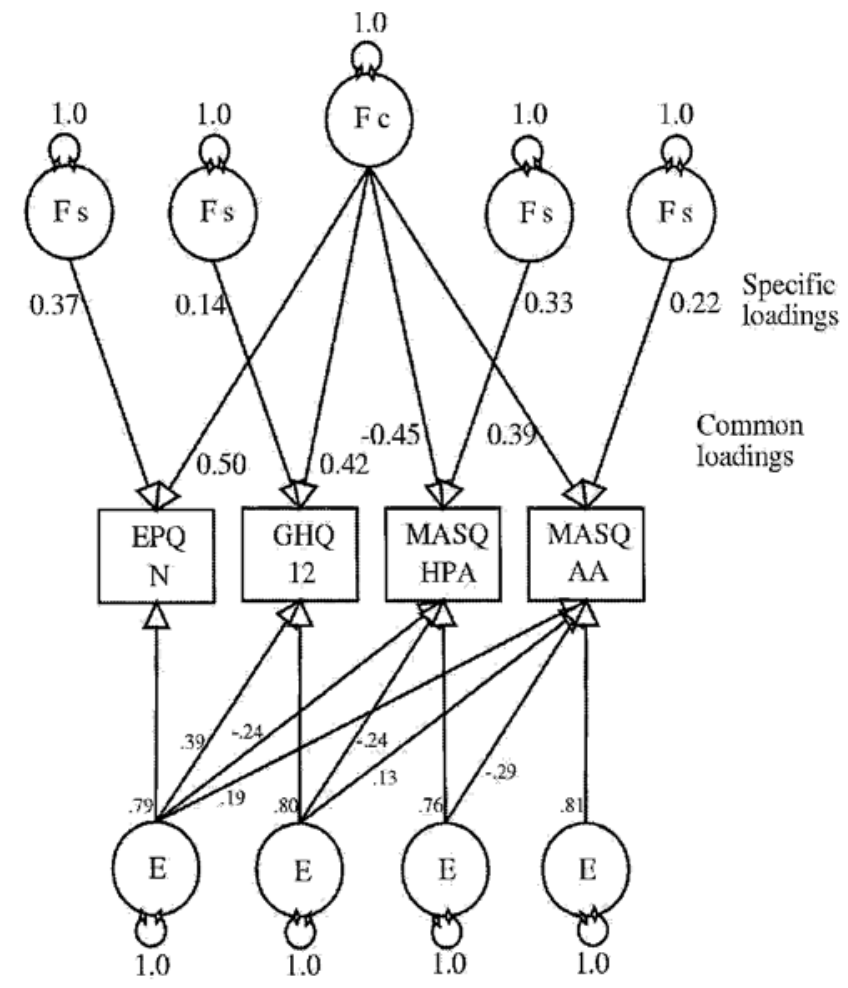

Key

$\mathrm{F} \mathrm{c}=$ Familial component (additive genetic and shared environmental) common to all measures.

$\mathrm{F} s=$ Familial components specific to individual mcasures.

$\mathrm{E}=$ Nonshared environmental components.

Figure1 Common familial factor model 


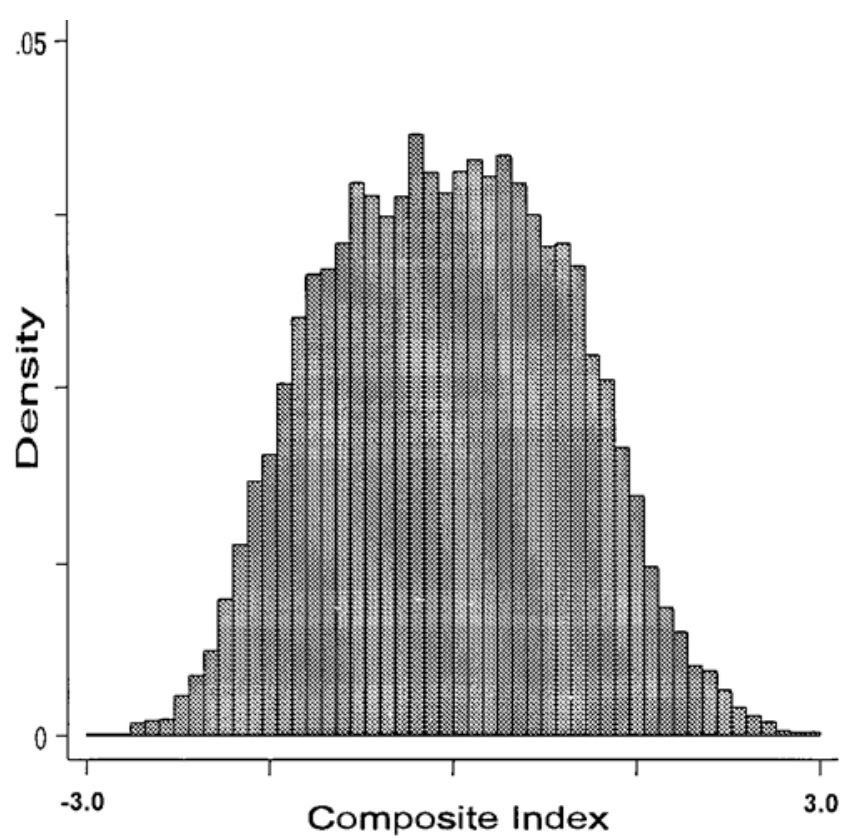

Figure2 Phenotypic distribution of the composite index derived from GHQ-12, EPQ-N, MASQ-HPA and MASQ-AA in the GENESiS sample

Table 6 Correlations between complete and incomplete composite indices $(n=19200$ individuals)

\begin{tabular}{llllll}
\hline & Complete & $\begin{array}{l}\text { EPQ-N } \\
\text { missing }\end{array}$ & $\begin{array}{l}\text { GHQ } \\
\text { missing }\end{array}$ & $\begin{array}{l}\text { HPA } \\
\text { missing }\end{array}$ & $\begin{array}{l}\text { AA } \\
\text { missing }\end{array}$ \\
\hline Complete & 1.0000 & & & & \\
EPQ-N missing & 0.9305 & 1.0000 & & & \\
GHQ missing & 0.9906 & 0.9001 & 1.0000 & & \\
HPA missing & 0.9568 & 0.8544 & 0.9309 & 1.0000 & \\
AA missing & 0.9679 & 0.8733 & 0.9504 & 0.9085 & 1.000 \\
\hline
\end{tabular}

about $30 \% .^{29}$ Heritability estimates from twin studies are higher, ${ }^{30}$ perhaps because monozygotic twin correlations include a greater amount of non-additive genetic variance than first-degree relatives such as siblings. ${ }^{31}$ This suggests that most of the genetic variance of neuroticism is additive, which is an important issue in relation to QTL analyses because non-additive genetic variance complicates attempts to find QTLs.

As hypothesised, quantitative genetic model fitting provided support for a single genetic vulnerability factor that is shared by EPQ-N, GHQ12, MASQHPA and MASQ-AA. We were able to derive from the parameter estimates of the best model a single composite index of the common familial vulnerability factor. This measure had a sib correlation of 0.22 , which is greater than the sib correlation of any of four component scales. The greatest contribution of EPQ-N to the composite index is consistent with the substantial evidence in the literature that EPQ-N is a relatively stable trait measure of emotional instabil- ity that is closely related to vulnerability to depression.

A limitation of the GENESiS project is the inability of the sib-pair design to separate out shared environmental influences from genetic effects. All heritability estimates derived in this study are therefore subject to the assumption that shared family environment is absent. However, while this assumption cannot be tested in GENESiS, it has been demonstrated to be approximately valid in Iarge-scale twin studies. $^{14,32}$

The ultimate aim of the GENESiS project is to identify quantitative trait Ioci (QTLs) for the shared genetic vulnerability to anxiety and depression rather than trying to identify QTLs separately for anxiety and depression. We also aim to characterise the interactions between these QTLs and psychosocial adversity in the aetiology of anxiety and depressive disorders. The demonstration of a single dimension of vulnerability to anxiety and depression in this sample of siblings offers support for adopting a QTL approach to genetic mapping. The composite index that we have constructed to measure this vulnerability dimension will be used in future molecular genetic studies on this sample.

\section{Acknowledgements}

This work was supported by MRC grant G9700821 and NIH grant EY-12562. We thank the general practitioners and the staff at the UK GP Research Framework who participated in this study.

\section{References}

1 McGuffin P, Owen MJ, O'Donovan MC, Thapar A, Gottesman II. Seminars in Psychiatric Genetics. Gaskell: London, 1994.

2 Plomin R, DeFries JC, McClearn GE, Rutter M. Behavioral Genetics. 3rd edn. WH Freeman: New York, 1997.

3 Rutter M, Plomin R. Opportunities for psychiatry from genetic findings. Br J Psychiatry 1997; 171: 209-219.

4 Angst J, Dobler-Mikkola A. The Zurich study. VI. A continuum from depression to anxiety disorders. Eur Arch Psychiatry Neurol Sci 1985; 235: 179-186.

5 Eaton W, Ritter C. Distinguishing anxiety and depression with field survey data. Psychol Med 1988; 18: 155-166.

6 Goldberg D, Bridges K, Duncan-Jones P, Grayson D. Dimensions of neurosis seen in primary care settings. Psychol Med 1986; 17: 461-471.

7 Kessler R, McGonagle KA, Zhao S, Nelson CB, Hughes M, Eshleman S, Wittchen HU, Kendler KS. Lifetime and 12-month preval ence of DSM-III-R psychiatric disorders in the United States: Results from the National Comorbidity Study. Arch Gen Psychiatry 1994; 51: 8-19.

8 Merikangas KR, Risch NJ, Weissman MM. Comorbidity and co-transmission of alcoholism, anxiety and depression. Psychol Med 1994; 24: 69-80. 
9 Ustan B, Sartorius N. Mental IIIness in General Health Care. John Wiley: Chichester, 1995.

10 Anderson J, Huppert F, Rose G. Normality, deviance and minor psychiatric morbidity in the community. Psychol Med 1993; 23: 475-485.

11 Goldberg DP, Huxley P. Common Mental Disorders: A Biosocial Model. Routledge: London, 1992.

12 Kendler KS, Heath AC, Martin NG, Eaves LJ. Symptoms of anxiety and depression in a volunteer twin population: The etiologic role of genetic and environmental factors. Arch Gen Psychiatry 1986; 43: 213-221.

13 Kendler KS, Heath AC, Martin NG, Eaves LJ. Symptoms of anxiety and symptoms of depression: Same genes, different environments? Arch Gen Psychiatry 1987; 44: 451-457.

14 Kendler KS, Neale MC, Kessler RC, Heath AC, Eaves LJ. A population-based twin study of major depression in women: The impact of varying definitions of illness. Arch Gen Psychiatry 1992; 49: 257-266.

15 Kendler KS, Walters EE, Neale MC, Kessler RC, Heath AC, Eaves $L J$. The structure of the genetic and environmental risk factors for six major psychiatric disorders in women: Phobia, generalised anxiety disorder, panic disorder, bulimia, major depression, and alcoholism. Arch Gen Psychiatry 1995; 52: 374-383.

16 Eaves LJ, Eysenck HJ, Martin NG. Genes, Culture and Personality: An Empirical Approach. Academic Press: London, 1989.

17 Jardine R, Martin NG, Henderson S. Genetic covariation between neuroticism and symptoms of anxiety and depression. Genet Epidemiol 1984; 2: 89-107.

18 Kendler KS, Neale MC, Kessler RC, Heath AC, Eaves LJ. A Iongitudinal twin study of personality and major depression in women. Arch Gen Psychiatry 1993; 50: 853-862.

19 Eaker S, Bergstrom R, Bergstrom A, Adami H, Nyren O. Response rate to mailed epidemiologic questionnaires: $A$ population-based randomized trial of variations in design and mailing routines. Am JEpidemiol 1998; 147: 74-82.

20 Etter J, Perneger T, Laporte J. Unexpected effects of a prior feedback letter and a professional layout on the response rate to a mail survey in Geneva. J Epidemiol Community Health 1998; 52: 128-129.
21 Goldberg DP, Gater R, Sartorius N, Ustun TB, Piccinelli M, Gureje O, Rutter $C$. The validity of two versions of the GHQ in the WHO study of mental illness in general health care. Psychol Med 1997; 27: 191-197.

22 Eysenck SB, Eysenck HJ, Barrett P. A revised version of the Psychoticism scale. Pers Individ Diff 1985; 6: 21-29.

23 Watson D, Clark LA, Weber K, Smith Assenheimer J, Straus ME, McCormick RA. Testing a tripartite model: 1. Evaluating the convergent and discriminant validity of anxiety and depression scal es. JAbnorm Psychol 1995; 104: 3-14.

24 Kendler KS, Neale MC, Kessler RC, Heath AC, Eaves LJ. A longitudinal twin study of 1-year preval ence of major depression in women. Arch Gen Psychiatry 1993; 50: 843-852.

25 Neale MC. Mx: Statistical Modeling. 4th edn. Department of Psychiatry, MCV, Richmond, VA, 1997.

26 Neale MC, Cardon LR. Methodology for Genetic Studies of Twins and Families. Kluwer Academic Publishers: Dordrecht, Netherlands, 1992.

27 Robins LN, Helzer JE, Weissman MM, Orvaschel H, Gruenberg E, Burke JD, Regier DA. Prevalence of specific psychiatric disorders in three sites. Arch Gen Psychiatry 1984; 41: 949-958.

28 Thomson GH. The Factorial Analysis of Human Ability. University Press: London, 1951.

29 Ahern FM, Johnson RC, Wilson $\mathrm{R}$, McClern GE, Vandenberg SG. Family resemblances in personality. Behav Genet 1982; 12: $261-280$.

30 Loehlin JC. Genes and Environment in Personality Development. Sage Publications Inc: Newbury Park, CA, 1992.

31 Plomin R, Caspi A. Behavioral genetics and personality. In: Pervin LA, John OP (eds). Handbook of Personality: Theory and Research, 2nd edn. Guilford Press: New York, 1999, pp 251-276.

32 Kendler KS, Kessler RC, Neale MC, Heath AC, Eaves LJ. The prediction of major depression in women: Toward an integrated etiologic model. Am J Psychiatry, 1993; 150: 1139-1148. 